\title{
"STEP INTO LEARNING WHEN READY": TOWARDS A STRENGTH-BASED APPROACH TO INDIGENOUS LANGUAGE EDUCATION IN A UNIVERSITY SETTING
}

\author{
Aleksandra Bergier ${ }^{1}$ \\ Queen's University \\ Kim Anderson \\ University of Guelph
}

\begin{abstract}
In the midst of nation-wide efforts to forge a path to reconciliation, Canadian universities have been working to transform the academic structures that perpetuate colonial patterns of domination and the erasure of Indigenous knowledges. Indigenization efforts often embrace the transfer of Indigenous languages as one of the critical pieces of Indigenous knowledge rejuvenation. However, for many Indigenous peoples, learning an Indigenous language brings up pain associated with family history and the legacy of residential schools. Language reclamation in a university environment occurs within the ongoing impact of colonial oppression and historic trauma transmission and therefore requires a trauma-informed approach. Based on qualitative research conducted at the University of Guelph with a goal to learn about the current Indigenous language education needs and challenges of the campus community, this paper explores a language revitalization strategy that accommodates different motivations and types of interest in Indigenous language learning as opposed to a "one size fits all" approach. The findings of the study point to a self-directed, non-penalty learning model aligned with Indigenous pedagogies. Within this model, language learning occurs in the right circumstances and at an appropriate time while respecting different levels of motivation and varied capacities for knowledge intake. The paper examines how an academic institution can shape the future directions in post-secondary Indigenous language programming by creating supports that address the impacts of intergenerational trauma and respond to diverse learning needs.
\end{abstract}

Keywords: Indigenous language revitalization, university education, Indigenizing the academy, trauma-informed education, Indigenous pedagogies

Citation: Bergier, A. \& Anderson, K. (2021). "Step into learning when ready": Towards a strength-based approach to Indigenous language education in a university setting. WINHEC: International Journal of Indigenous Education Scholarship, 16(1), pp. 12-46. http://dx.doi.org/10.18357/wj1202120273. Special Issue on Indigenous Language Revitalization: Innovation, Reflection and Future Directions, Guest Co-Editors Drs. Onowa McIvor and Kari A. B. Chew.

\footnotetext{
${ }^{1}$ Correspondence: Aleksandra Bergier, Queen's University, a.bergier@queensu.ca
} 


\section{Introduction}

Over the last decade, Indigenous and allied scholars have persistently advocated for decolonization of the academy (Battiste, 2013; Brant Castellano, 2014; Gaudry \& Lorenz, 2018; Kuokkanen, 2011; Mitchell et al., 2018). “Indigenization,” used as part of this larger project of decolonizing the academy, is an umbrella term addressing a variety of endeavours aimed at integrating Indigenous perspectives and ways of being into the experience and delivery of post-secondary education. It ranges from long-term comprehensive strategies attempting to deconstruct the colonial ideologies and practices that underlie the academy to quick-fix (and much needed) solutions such as boosting the number of Indigenous faculty members.

Language revitalization plays an important role in Indigenization processes. Forty-six percent of the world's languages are at risk of disappearing and many of these languages are Indigenous (Campbell \& Belew, 2018). In order to draw attention to the progressive language loss, the United Nations has declared an International Decade of Indigenous Languages, set to start in 2022. The Los Pinos Declaration [Chapoltepek] (UNESCO, 2020) outlines the key principles, goals, and outcomes of the International Decade, which seeks to mainstream Indigenous languages across public policies including those related to education, culture, media, environment, health care, and employment.

Canada is home to more than 70 Indigenous languages belonging to 12 language groups (Statistics Canada, 2017); however, the majority are in decline with a decreasing number of speakers (Brittain, 2002; McIvor et al., 2009; Shaw, 2001). The Truth and Reconciliation 
Commission of Canada (2015) stressed the right of Indigenous peoples to preserve their ancestral languages and urged post-secondary institutions to foster language and culture development in higher education. Recommended actions include creating university and college degree and diploma programs in Indigenous languages and providing funding to educate teachers about integrating Indigenous knowledge and teaching methods into classrooms. A growing number of Canadian universities are now responding to the Truth and Reconciliation Commission of Canada (TRC) Calls to Action (2015) with respect to Indigenous language education by offering programs in Indigenous languages, creating language research and training centres, co-creating language courses through partnerships with Indigenous communities, and supporting immersive, community-based experiential learning (Bliss \& Breaker, 2018; Council of Ontario Universities, 2017; Czaykowska-Higgins et al., 2017; Green, 2017; McCue, 2016; McIvor \& Anisman, 2018). To our knowledge, no university in Canada offers a $\mathrm{PhD}$ program specific to an Indigenous language or languages.

Within the Canadian context, Indigenous language loss is the result of the colonial state's systematic efforts to dismantle Indigenous cultures through genocide, forced relocation, oppressive policies and legal frameworks, the Sixties Scoop and the residential school system (Bombay et al., 2009; McIvor \& Anisman, 2018). Contemporary scholarship on language reclamation indicates that Indigenous and minority language use occurs within the ongoing legacy of colonial oppression and historic trauma transmission, which have been deeply detrimental to the holistic wellbeing of individuals and communities (Meissner, 2018; Skrodzka et al., 2020; Whalen et al., 2016). The intergenerational trauma associated with the residential school system, where Indigenous children experienced severe punishment for 
speaking their languages and practising their cultures, continues to negatively impact the success of Indigenous students today, pointing to the need for trauma-informed pedagogical approaches (Bombay et al., 2013; First Nations Centre, 2005; Gaywish \& Mordoch, 2018; McIvor et al., 2018; Mordoch \& Gaywish, 2011; Ontario Federation of Indigenous Friendship Centres [OFIFC], 2016). Gaywish and Mordoch (2018) describe a trauma-informed approach to education as one in which people who are engaging with the students (teachers, program planners, and administrators) understand intergenerational trauma and are able to create responses that facilitate healing.

Acknowledging the effects of trauma and building trust are also fundamental to traumainformed education. In a study involving urban Indigenous high-school students in Ontario, the OFIFC identified the following practices as necessary for developing trauma-informed education: recognizing Indigenous culture; forming respectful, trusting, and supportive relationships; acknowledging teachable cultural content such as Indigenous languages, histories, and art; cultivating an awareness of how trauma impacts Indigenous students' school experiences; ensuring urban Indigenous peoples are included in trauma-informed educational planning; and using multi-sector approaches to conduct research and create policy on how schools can create trauma-informed environments (OFIFC, 2016). Other key components of trauma-informed approaches may include adopting individualized learning and fostering holistic education through formal and informal pedagogies (Aguiar \& Halseth, 2015). 
In spite of stressors that stem from historical trauma and interfere with Indigenous peoples' learning as they work towards healing and recovery, academic environments can create unique opportunities for nurturing Indigenous identity and Indigenous knowledge and language revitalization and can contribute to building meaningful settler allyship. Indigenous students, scholars, and Knowledge Keepers increasingly note the potential of post-secondary institutions to spearhead social change and positively impact the health of Indigenous campus community members by becoming meaningful sites for language learning (Czaykowska-Higgins et al., 2017). Post-secondary institutions can be places where many Indigenous learners experience Indigenous ways of being and knowing for the first time (Cull et al., 2018; Mitchell et al., 2018; University of Guelph, Mohawk College, \& Six Nations Polytechnic n.d.). Following this strength-based approach, our paper presents the key results of research involving campus community members at the University of Guelph. In our report on the findings below, we start with the current gaps and obstacles with respect to culturally safe Indigenous language programming at the University of Guelph and then offer insights and analysis on future supports needed to create new, exciting venues and mechanisms for Indigenous language delivery.

\section{Methodology and Locating Ourselves}

The authors of this paper identify as a Métis scholar, writer, and educator working in the discipline of Indigenous Studies (Anderson) and a Polish settler researcher who has been exploring language revitalization strategies in collaboration with Indigenous communities (Bergier). Together, we embarked on a research journey to learn how the University of Guelph-situated on the Dish with One Spoon territory and the treaty lands of the 
Mississaugas of the Credit (and at the time of the study a home institution to both of us)can facilitate a safe and strength-based environment for Indigenous language learners while addressing a sense of cultural loss and linguistic insecurity.

Our study employed qualitative research methodologies involving thematic analysis of interview and workshop material (Braun \& Clarke, 2013) and Indigenous research methodologies emphasizing the value of community engagement towards the revitalization of Indigenous knowledge, attention to relationships, and strength-based vs. deficit approaches (Drawson et al., 2017; Smith, 1999; Tuck, 2009; Wilson, 2008). Our team began with an environmental scan of the current Indigenous language education initiatives, needs, and challenges, and then we sought out stories from the University of Guelph campus community. In collaboration with the Indigenous Student Centre (ISC), we held interviews and conducted workshops using "kitchen table theory and methodology" (Farrell-Racette, 2017) and the Métis notion of "visiting space" (Carrière \& Richardson, 2016). Our goal was to collect stories through the use of welcoming working spaces that foster inclusiveness, collective dreaming, connection to land, and creativity. In so doing, we sought to honour Wahkotowin-a Cree principle underscoring the importance of being related to each other and all things in creation (Anderson, 2011; Reder, 2007; Robbins et al., 2017).

We gathered data from 25 interviews with campus community members and through one land-based and one art-based workshop attended by a total of 13 participants. The workshops involved an Elder's teachings and sharing circles with a focus on Anishinaabemowin. The project engaged both Indigenous and settler campus community 
members: students, faculty and staff, as well as Indigenous Elders and Knowledge Keepers who provide supports to the campus community. We conducted one-on-one interviews using a semi-structured questionnaire. The workshop participants were recruited by posters, and the interview participants were invited through our professional contact list or via email using publicly available contact information. We also advertised our workshops through the university's Indigenous Student Society and ISC networks to ensure the participation of Indigenous youth and to provide them with an opportunity to voice their needs and express their diverse identities, relationships, and responsibilities in relation to Indigenous languages. Interview and workshop transcripts were coded thematically using NVivo qualitative analysis software.

A starting place for us was that most buildings at the University of Guelph are named after university senior officials and educational philanthropists, with no reference to the traditional territories Guelph is situated on nor the Indigenous peoples who have occupied them. As part of our land-based workshop, we invited students, faculty, and staff members to take a unique walk around campus and use Anishinaabemowin to symbolically re-name several university buildings with a help of an Anishinaabe Elder and artist Rene Meshake. The Anishinaabemowin word bundles ${ }^{2}$ were gifted by Rene in reference to specific buildings and were inspired by stories the participants shared with us about the everyday campus environments where they live, study, and work. Rene connected these stories with teachings

\footnotetext{
${ }^{2}$ As explained by the Anishinaabe Elder Rene Meshake, the process of creating Anishinaabemowin word bundles consists of breaking down words to unpack their meaning through storytelling. See his work in Rene Meshake and Kim Anderson, Injichaag: My Soul in Story, Anishinaabe Poetics in Art and Words (University of Manitoba Press, 2019).
} 
about kinship, land use, trapping, and hunting specific to his home territory. The participants shared their thoughts about the walk during a sharing circle combined with a "Soup and Bannock Day" at the ISC.

During our art-based workshop at the ISC, the participants created a collaborative art piece inspired by the concept of Anishinaabe birch bark scrolls. Instead of birch bark, the participants used colourful images torn out of magazines, creatively reconfigured to create a vibrant collage filled with new meanings and the collective understanding of Indigenous language revitalization and stewardship of the land. As the participants were explaining the meaning of their individual art pieces during a sharing circle, Rene gifted them with humorous stories and word bundles inspired by what he saw in the scroll. Both workshops provided for a rich audiovisual documentation and several creative outputs such as digital stories, word-bundle teaching sheets, and students' artwork.

\section{Indigenous Language Learning Landscape in Canadian Post-Secondary Education}

Currently, more than 30 Indigenous languages are taught at Canadian universities (Universities Canada, 2017). Programming varies institutionally and may include courses, certificates, minors, and majors, as well as Indigenous language revitalization undergraduate and graduate programs. Degree programs are relatively rare. Some noteworthy examples include the Mohawk and Cayuga Bachelor of Arts at Six Nations Polytechnic, the Bachelor of Arts and Honours in Cree and Saulteaux at First Nations University of Canada, a three-year undergraduate Anishinaabemowin program at Algoma University, and Simon Fraser University's Linguistics of a First Nations Language Master of Arts. The University of Guelph's 
School of Languages and Literatures started offering its first-ever Indigenous language (Anishinaabemowin) introductory course in the fall of 2019.

Several post-secondary language revitalization initiatives highlight the importance of reconciliation in action and commitment to serving local Indigenous communities. One example of such an approach is St. Xavier University's decision to offer introductory and advanced Mi'kmaq language classes in response to the call of Mi'kmaq community to help with the revitalization efforts (Association of Canadian Deans of Education, 2011).

Three main strategies in formal adult Indigenous language acquisition are language classes, group-based immersion, and individual, self-directed approaches such as Master-Apprentice Program (MAP) and Accelerated Second Language Acquisition (ASLA) (McIvor, 2015). Immersion has been reported as one of the most effective strategies for revitalizing Indigenous languages and producing fluent speakers (Grenoble \& Whaley, 2006; Hermes, 2007; Hinton, 2003), and research has demonstrated that this method has a positive impact on enhancing students' overall academic achievement (Harrison \& Papa, 2005; McCarty, 2003; McIvor, 2005). In line with these findings, several post-secondary institutions are implementing or planning to implement partial or full immersion approaches in Indigenous language education. For example, Six Nations Polytechnic commissioned a study about critical paths to second language acquisition of Onkwehón:we languages with the participation of the teachers, learners, students, speakers, and administrators of Six Nations' community language programs. This study defined the components critical to acquiring the Onkwehonwehnéha, created a speaker profile, and examined efficient strategies in 
improving language proficiency ${ }^{3}$ for the purpose of creating a critical mass of second language speakers at Six Nations. The recommendations include establishing and maintaining four-year adult immersion programs within an interactionist approach that offer at minimum 3,600 hours of contact time, necessary to successfully move the learner through the five stages of language acquisition specific to Onkwehón:we languages (Green, 2017).

In some instances, the efforts and priorities pursued by the universities with respect to Indigenous language revitalization appear to be ambiguous and limited to the realm of symbolic recognition. Initiatives such as developing a single language course or creating campus signage in Indigenous languages may be perceived as superficial if not accompanied by multipronged strategies aimed at addressing systemic barriers and designing solid educational pathways for those committed to attaining language fluency. ${ }^{4}$ Certainly, some post-secondary institutions, for example Gabriel Dumont Institute, jumpstarted their language education by building awareness and intellectual curiosity around Indigenous languages as a step towards further educational pursuits such as learning in a community setting (Sterzuk \& Fayant, 2016). Others, like the University of Victoria with its sophisticated laddered approach and a comprehensive Indigenous language revitalization degree program, address multiple goals at once by producing language speakers, teachers, planners, and advocates. This is achieved through a system of offerings informed by the Indigenous communities and language stakeholders that allows the students to move through

\footnotetext{
${ }^{3}$ Language proficiency is defined as "the ability to use a language in real-world situations, in a manner acceptable and appropriate to native speakers of the language" (Kahakalau, 2017, p. 3).

4 Fluency can be described as a "speedy and smooth delivery of speech without (filled) pauses, repetitions, and repairs" (De Jong et al., 2015, p. 224).
} 
community immersion and a series of certificates and diplomas in order to achieve Indigenous language proficiency and teacher qualifications (Czaykowska-Higgins et al., 2017; Liddicoat, 2018; McIvor \& Anisman, 2018; McIvor et al., 2018).

When analyzing the state of Indigenous language delivery at Canadian universities, it is important to differentiate between aspirational reconciliation and decolonial resurgence (Gaudry \& Lorenz, 2018). The latter requires the universities to advance a "re/connection to the land, language and people of this land ... and support those land, language and cultured based organizations that have already been doing indigenization work ... but haven't had the financial support" (Gaudry \& Lorenz, 2018, p. 224). This differentiation is especially relevant in the view of the findings of the First Peoples' Cultural Council Report on the Status of the B.C. First Nations Languages, which states that "current Western education models are failing Indigenous peoples; things need to be done differently. Language instruction (ideally immersion) should be the keystone of educational policy" (p. 29). The report urges the universities "to respond to community needs by building programs that work towards building fluency" and "prioritize and support increased language teacher training" (Dunlop et al., 2018, p. 29). As noted by Corbiere (2019), if universities wish to play a leading role in supporting or advancing Indigenous language reclamation, they should create full-time, tenure-track, and tenured positions for Indigenous language teachers; support them in developing urgently needed, comprehensive learning materials; and help implement methods that actively foster continuous exposure to Indigenous languages. 


\section{Trauma, Language Loss and Experiences of Indigenous Learners}

The population of Indigenous students at Canadian universities is very diverse in terms of professional and educational backgrounds, age, community of origin, residency, mobility patterns, cultural affiliation, and Indigenous language competency (Cull et al., 2018; Environics Institute, 2010). Indigenous peoples who come to post-secondary education may face a wide array of identity-related challenges, such as a sense of disparity and disconnect from communal life and extended kinship system, as well as the need to find viable, culturally appropriate services (Carli, 2012; Cull et al., 2018; Indspire, 2018). Furthermore, these individuals find themselves in different places in terms of exploration of their cultural identity. Coming from diverse backgrounds, members of Indigenous communities represent different levels of cultural awareness. Many do not grow up with opportunities to explore Indigenous teachings and encounter limited options to learn about their ancestry through the school system. They may begin the self-exploration journey in their adulthood and strive to piece together the stories of the past. Such attempts, however, are not always nurtured by a supportive educational environment, especially when the students are tokenized and expected to have extensive cultural knowledge or language that wasn't shared with them (Profitt, 2000; Young et al., 2012).

Intergenerational trauma rooted in colonial oppression, and specifically the trauma associated with the residential school system, continues to severely impact the educational experiences and learning outcomes of Indigenous peoples in Canada, putting them in an extremely vulnerable position when confronted with mounting social and academic pressures. Similar to symptoms suffered by residential school survivors, the subsequent 
generation of Indigenous peoples may also be highly susceptible to stressors that originate from unresolved grief such as thoughts associated with the loss of language, land, and culture, and may in turn experience more elevated levels of psychological distress (Whitbeck et al., 2004; Bombay et al., 2013). In addition to having their lives shaped by emotional responses to historic wrongs, Indigenous learners pursuing post-secondary education may struggle with the ongoing effects of trauma "manifested as self-doubt, feelings of incompetence, living with alcohol and addictions, difficult family dynamics, and difficulty coping with the stresses and challenges of being a student" (Gaywish \& Mordoch, 2018, p. 11). They are also likely to experience a disrupted sense of belonging and a fear of not having enough knowledge about their heritage (Young et al., 2012). The struggle becomes painfully visible in the classroom setting, where the Indigenous students tend to be singled out for participation under an assumption that they are knowledgeable about Indigenous issues and should therefore eagerly share a "community experience," such as living on reserve (Borrows, 2010).

Similarly, the fact of not knowing one's ancestral language or having limited language proficiency can generate profound feelings of loss, shame, personal failure, and cultural incompetency among Indigenous non-speakers as well as dormant or incipient speakers (Albury, 2015; Bergier, 2015). The efforts required to learn an Indigenous language are tremendous. Being asked a seemingly simple question such as "do you speak your language?" can cause members of Indigenous communities to feel ostracized and unfairly judged for not having the knowledge they are expected to have (Dion \& Salamanca, 2014). Indigenous youth can perceive language loss as a deeply personal experience, while disregarding structural and long-term colonial processes such as oppressive laws, intergenerational trauma, and 
displacement that contributed to language dispossession and shaped their identities as nonspeakers, "forgetters," or "linguistically insecure" individuals (Wyman, 2012, p. 203).

\section{Findings}

\section{Navigating the challenges: Personal struggles, institutional barriers and the fear of unsafe learning environments}

The troubling experiences described above resonate with stories recounted by several Indigenous participants in our study wherein they indicated feelings of shame and dispossession associated with the inability to speak their ancestral language or with not speaking it well enough. These feelings impact their willingness to pursue or continue Indigenous language learning. Among the Indigenous staff and faculty who shared their language stories with us, this sense of shame and loss was often exacerbated by statements from peers implying that not knowing one's language is synonymous with not knowing one's culture. These painful feelings often coexist with a conviction that language revitalization is indeed a vital component of Indigenous resurgence and a significant step in rectifying the wrongs of assimilative policies. However, a fair amount of personal healing and solid institutional and community supports are often needed before an individual is ready to engage in Indigenous language education. It is important to note that the discourse equating not knowing one's language with not knowing one's culture points to a narrow purist understanding of what it means to thrive as an Indigenous person. It delegitimizes the wealth of other identity markers and cultural practices that have been kept alive at great cost by Indigenous communities. Contrary to that discourse, several participants asserted that the 
ability to speak an Indigenous language is but one of many components of dynamic, ever evolving, and vibrant Indigeneity.

The settler participants' attitudes towards learning Indigenous languages through campusbased activities were also reflective of how their identities might factor into the learning process and how they might position themselves within these initiatives. One settler participant disclosed that they did not grow up with knowledge about Indigenous issues and expressed anxiety about not fitting in/not behaving correctly in an Indigenous language course. Other settler participants discussed the need to embed language revitalization within the broader context of a shared history. They suggested creating preliminary learning opportunities to get a better perspective of the current Indigenous-settler relations and to understand how Indigenous languages were impacted by colonialism.

Most Indigenous and settler participants viewed learning an Indigenous language as a demanding process that requires a great deal of personal sacrifice and a multipronged support structure. Several participants made a distinction between "learning an Indigenous language" and "becoming familiar with an Indigenous language." They saw the former as an intimidating task to be undertaken by a smaller group of committed learners while the latter was perceived as a more general endeavour with the participation of a broader campus community. Participants associated learning an Indigenous language with high levels of proficiency-a challenging goal and one that would be difficult to accomplish by all. Several participants, however, thought that the University of Guelph should offer both a pathway for highly engaged learners to achieve proficiency and, at the same time, opportunities for 
students and employees to learn about culturally relevant vocabulary and acquire basic communication skills in an Indigenous language.

There were many comments about challenges related to heavy workload and limited availability to engage in language activities. Students reported experiencing significant pressures in terms of their academic performance and achieving a desirable Grade Point Average (GPA). Some students would welcome an option of taking an Indigenous language as an elective because their current course load allows them to engage in few extracurricular activities. Others preferred an option to pursue Indigenous language learning as additional to their normal course of study. The early career researchers who spoke with us acknowledged that an investment in Indigenous language activities (and other types of Indigenous cultural programming for that matter) might pose a career risk given their teaching, research, and service load. Learning an Indigenous language is not currently considered to be an official upgrade in professional skills at the University of Guelph, although several Indigenous faculty and staff members indicated that a change in that regard would certainly be welcome.

Some Indigenous participants spoke about the lack of respectful acknowledgment of the use of Indigenous languages in their academic work. Although the official university discourse promotes inclusivity, it is not always embraced as an institutional practice. One individual reported receiving pushback after using Indigenous words in their written assignment. Another participant said that in addition to teaching Indigenous languages, the academic 
leaders and educators should also respect and encourage the use of these languages in research.

Although most participants agreed that it is important for the campus community members to learn an Indigenous language-at least to some extent-and pointed out that the university has a fundamental role in creating non-elitist and accessible learning options for a variety of audiences, some individuals questioned whether the academic institutions are truly capable of creating culturally safe language programs that follow the holistic principles of contextually rich land-based education. Participants raised concerns about implementing language initiatives without proper consultation and engagement with Indigenous peoples. They questioned promoting an academic understanding of an Indigenous language rather than a community-based one, as academic programming may result in taking the language revitalization leadership and funding opportunities away from Indigenous communities. Some participants were also worried about racist attitudes and potential pushback against Indigenous language initiatives that may taint the experiences of prospective learners. Nevertheless, participants agreed that preserving Indigenous languages in all institutional domains, including academia, is an urgent task. They stated that offering post-secondary opportunities for language learning is a goal that needs to take precedence over the fear of unsafe educational environments, cultural appropriation, and the possibility of mishandling Indigenous content. 


\section{Setting new directions for the post-secondary Indigenous language education: An empowered learner is a self-directed learner with adequate institutional supports}

Several Indigenous research participants indicated that pedagogical practices that accommodate personal vulnerabilities could remediate psychological harms associated with self-critical perfectionism or the fear of "not being good enough." Most of the Indigenous staff and faculty also noted the fundamental importance of cultural safety to a positive postsecondary language learning experience. Overall, the following components were viewed as critical to creating a safe learning environment: kind, gentle, and culturally knowledgeable teachers; a caring space for honest conversations and for the participants to share their challenges and struggles if desired; and a fun, self-directed pedagogical model that rewards all efforts and recognizes that making mistakes is key to learning.

A number of participants considered it essential for language education to be firmly embedded in Indigenous ways of knowing and being; this came up especially among the Elders who repeatedly spoke of the need to build wellness and support the development of a language learner as a whole. Participants who were familiar with the verb-based and actionoriented structure of Anishinaabemowin felt it was imperative for the future students to "learn by doing"; to perform the language through their speech and bodies, preferably in a culturally meaningful context, enhanced by storytelling and seasonal observations. Storytelling would allow the learners to embed the language in the land-connecting it back to the sounds heard in nature-and in relationships with each other. Some of the settler participants echoed the words of Indigenous Elders who often emphasize that there is no real reconciliation without the reconciliation with the land-the source of sustenance for all. They 
described reconciliation as deep listening—being attentive to Indigenous concepts that refer to interrelationality and a sense of home.

Indigenous faculty, staff, and Elders raised the idea of a teaching lodge. They envisioned this as an egalitarian, ceremonial space joined together by reciprocity and shared intentions-a community circle where everybody can express their unique gifts and responsibilities regardless of proficiency levels. For example, one Elder described Anishinaabemowin as an expansive language with multiple levels of communication and noted that the learning strategy should reflect this reality through a dynamic back and forth within a circle of practitioners who hold different pieces of language wisdom and are co-creating their learning experience.

Another issue discussed by the participants was the diversity of students' identities and interests in language learning. These individuals find themselves in different roles and places in terms of asserting connection to their cultural practices as Indigenous peoples and fulfilling their responsibilities as allies in the case of the settler learners. When we asked the Indigenous campus community members about their interest and motivation in Indigenous language learning, the responses varied considerably. Some individuals perceived Indigenous language acquisition as a rite of passage, a process that's sacred and fundamental to reclaiming Indigenous heritage, recreating Indigenous homelands, understanding the complexity of ancestral teachings, and revealing the truth of who they are as people. Others saw Indigenous language learning within a university setting as a potential incentive for young people to reconnect with their communities and learn about their culture with a 
renewed interest that they can subsequently share with their peers. Some participants didn't see Indigenous languages as indispensable to personal cultural reclamation. To those participants, learning a language would mean enhancing and deepening an already existing understanding of one's culture and responsibilities. Similarly, for individuals who identified as being of mixed Indigenous/non-Indigenous ancestry, language learning was but one component of identity negotiation, although it was seen as helpful in strengthening kinship with the Indigenous side of their family and community. One participant viewed language learning as an intimidating first step in exploration of one's ancestry and preferred to delve deeper into other aspects of Indigenous culture.

When we discussed these issues with the settler participants, many talked about the shared responsibility to honour the land and its original stewards by supporting Indigenous peoples in language revitalization efforts. While recognizing that as settlers they continue to benefit from Canada's colonial past, they also acknowledged the sense of solidarity originating from experiences of displacement, discrimination, and dispossession some newcomer groups share with Indigenous peoples. Furthermore, learning an Indigenous language in a familyoriented intergenerational context would be meaningful to settlers who wish to pass the history of the land, including place and food names, to their children. Other participants brought up their responsibilities as professionals engaged in work with Indigenous communities. These individuals saw picking up some language as vital to relationship building and understanding of Indigenous teachings, but also to professional development. 
Without dismissing the importance of earning academic credits for Indigenous language activities, several participants discussed combining the credit system with a non-penalty, strength-based model of language education where learning would occur in the right circumstances and at an appropriate time while respecting different levels of motivation and varied capacities for knowledge intake. For example, the participants suggested an option to take a language course multiple times until both the learner and the instructor agree that the knowledge was grasped to a sufficient extent and in a good way. The non-penalty model also recognizes that knowledge seekers need to step away from their learning commitments if the moment is not right, if they need to focus on fulfilling responsibilities to their families and communities, and for a variety of other individually-focused reasons. Participants stated that taking a break should happen without fear of failing a course/exam and the pressure to achieve a predetermined level of language competency. They pointed out that this approach should be complemented by an access to the community of practitioners-an established support system for the students to fall back on if at some point they choose to resume language learning. Furthermore, the participants thought that learners' performance should be evaluated within open-ended, individually crafted formats that demonstrate a personal level of language understanding and accommodate different learning styles (examples may include making a video, telling a story, presenting art or poetry, or engaging in an experiential activity).

A number of settler and Indigenous participants thought that the access of Indigenous students to language learning opportunities should be made a priority in order to accommodate the needs of those who didn't have the chance to learn their ancestral 
languages in a family/community setting or for those who need to apply the language knowledge in their research projects. The participants also acknowledged that some of the environments dedicated to language transfer, and particularly the healing ceremonial spaces, should also understandably prioritize the access of Indigenous peoples.

The research participants made it clear that language revitalization is only one component of a collective decolonization journey. Hence, the institutional supports should not be limited to language development but should encompass greater inclusion of Indigenous knowledges across the university initiatives. This was described by some of the participants as the "incremental process of culture change" that may require, for instance, incorporating a fulltime Elders' council into the university structures and building governance models that give Indigenous peoples control over a broad range of matters that affect their interests within an academic setting, such as the power to make financial decisions about Indigenous language support.

Several participants noted that instead of being restricted to classroom or workshop learning, Indigenous language use should pervade different social contexts on campus. Participants offered several examples of Indigenous language use domains, including digital signage as well as multilingual street signage on campus; inclusion of Indigenous vocabulary in the naming of food items in the cafeteria; as well as in the naming of buildings, offices, gardens, and outdoor kitchens. Other suggestions included creating spaces for immersion such as students' language houses; pairing the campus and Guelph maps with Indigenous historical place narratives and etymological information; and using Indigenous vocabulary in essays, 
research papers, reports, theses, and presentations. For those students and researchers who wish to apply Indigenous vocabulary in their academic work, the participants proposed the creation of a living language database with a list of words and their use vetted by language keepers and practitioners.

Some participants noted that the pathway to Indigenous language revitalization starts prior to implementing language activities on campus. They noted there might be reluctance among Indigenous students to self-identify for fear of potential discrimination and that academic institutions have an important role to play in breaking down barriers, reaching out to Indigenous communities, and building inclusive environments where Indigenous cultures and languages can thrive. The examples they provided included building pathways into degree studies for Indigenous peoples and creating academic bridging courses for mature Indigenous students. Other recommendations focused on the inclusion of Indigenous language components in curriculum throughout the university's academic programs, inviting language keepers to class as guest speakers, and approving Indigenous language courses as electives across all colleges and departments.

The participants pointed out that a university commitment to supporting Indigenous language resurgence ought to involve long-term funding and assistance toward developing teaching resources, including language materials and applications. This could result in a gradual strengthening of institutional capacity to deliver language programming so that it might eventually evolve into a degree program. Several participants saw it as vital that the institution incorporate Indigenous language keepers as tenured academic staff and as 
language resource experts, as this would provide support for students who are interested in incorporating languages into their projects. This would also build capacity when paired with succession planning and empower the new hires to take the lead on the curriculum development. The staff and faculty members felt that it would be immensely helpful if the university officially recognized Indigenous language training (adult immersion, language camps, master-apprentice programs) as part of professional development for Indigenous and allied faculty and staff.

\section{Discussion}

Language revitalization within the university setting is a significant step towards reconciliation and a critical priority in the implementation of the TRC Calls to Action. Determining the desired level of Indigenous language competency is complex, and although the literature points to the importance of building proficiency and the creation of new adult speakers and teachers (Czaykowska-Higgins et al., 2017; Dunlop et al., 2018; Green, 2017; McIvor et al., 2018), it became clear in the course of our research that the University of Guelph should offer diverse learning options targeting the audiences who wish to reach basic language competency along with those committed to attaining proficiency. Supporting specific language initiatives is not enough to move beyond aspirational reconciliation (Gaudry \& Lorenz, 2018). Language revitalization strategies within post-secondary institutions must also focus on removing systemic barriers that prevent students from using Indigenous languages in different social domains on campus, and they must create institutional pathways to increase Indigenous enrolment and nurture inclusivity. Language 
use and visibility at the University of Guelph were viewed as key to raising awareness about Indigenous peoples' cultural continuity—an everyday act of resurgence and perseverance.

Within this push to integrate Indigenous language learning in post-secondary institutions, several of those we interviewed shared concerns about the lack of culturally safe environments. They called for spaces where Indigenous campus community members who experience impacts of historic loss in their daily lives can safely express vulnerability, assess personal readiness to learn with the support of peers, and set individually tailored language learning goals. What we heard during our interviews and workshops was that a caring space for language learners to express their needs and build on the skills and interests they already have is as critical as developing an innovative curriculum. Although the participants did not explicitly refer to these practices as trauma-informed, their descriptions of a desired learning environment were generally in line with scholarship on trauma-informed approaches from an Indigenous perspective. Themes such as individualized learning strategies (Aguiar \& Halseth, 2015), a focus on cultural safety and Indigenous content (OFIFC, 2016), and the acknowledgment of impacts of intergenerational trauma (Gaywish \& Mordoch, 2018) recurred at various points throughout our research. As suggested by McIvor et al. (2018), issues of trauma and pain associated with language loss impact both the Indigenous language mentors and students but may be remediated through targeted approaches such as instructor-learner agreements that describe the supports needed to create a safe environment for language recovery. Based on our findings, such agreements could specify the needs, interests, and motivations of learners and mentors; address their identity and kinship responsibilities; and determine what constitutes a satisfactory level of language 
knowledge using individually crafted assessment strategies. Lessons learned in the context of trauma-informed education in urban Indigenous communities, and specifically the importance of building trusting relationships between students and people in positions of authority within the school system (OFIFC, 2016), are certainly applicable to university Indigenous language program design. Trauma-informed education may be enhanced through culturally appropriate, meaningful dialogue between the prospective learners and the university officials, teachers, educational planners, curriculum developers, and administrators.

Navigating the diversity of interests and motivations requires attentiveness to students' language learning histories and connecting teaching strategies to their goals, strengths, preferences, background knowledge, and experience (McIvor, 2015). One way to address diverse learning needs and build on the existing resources and skills of students is to offer a multitude of experiential entry opportunities to language learning. Participants in our study recommended activities such as cooking classes using traditional Indigenous foods; medicine, arts, and beading workshops; storytelling sessions; service and relationship building opportunities in Indigenous communities; land-based programming, for example language hikes or canoe trips; and seasonal camps and family/intergenerational learning activities.

What stands out as being of particular significance-and what may further enrich the current discussion about trauma-informed education within a university setting-is the participants' suggestion to foster a non-penalty model that would allow the learners to take a language course/participate in a language learning activity multiple times. From this standpoint, 
strengthening of the institutional capacity around Indigenous language delivery would not be limited to formal offerings within the academic credit-based system, but it would also incorporate semi-formal language initiatives that may or may not be counted towards credits on a case-by-case basis.

In a study about the interplay between trauma and resilience in the post-secondary educational experiences of Indigenous adult learners, Lindstrom (2018) notes that "in suffering we foster our resilience but this resilience is not confined to individual mettle but cultivated in relationships and sources of inspiration which are strewn along our life pathways and nudge us onward" (p. 179). Establishing a core community of practitioners (a teaching lodge) who would share their knowledge of language and cultivate meaningful relationships in a relaxed, land-based and family-friendly setting could potentially manage the threatening aspects of language acquisition, such as self-critical perfectionism and fear of failure. As we completed this work, a group of Indigenous community-engaged scholars put forward a proposal for "Nokom's House" - an Indigenous land-based research lab and a "grandmother-centred" space that could address several recommendations of our study by facilitating opportunities for creative endeavours, ceremony, visiting, learning, cooking, and language work. This is but one example of how our findings might add to language revitalization efforts undertaken at Guelph and elsewhere.

\section{Conclusion}

We set out to investigate the possibilities for integrating Indigenous language learning at the University of Guelph, and in so doing, to add to the scholarship on Indigenous language 
learning at a time when institutions are exploring how they might "Indigenize" the experience and delivery of post-secondary education. Our research demonstrates that strength-based, trauma-informed approaches are necessary in order to provide culturally safe learning opportunities for Indigenous language learners. We confirmed that traumainformed education is a good pathway for Indigenous language learning because of the shame and a sense of cultural dispossession among Indigenous peoples who have lost their languages due to assimilation policies. Building on the tremendous work of language revitalization in other post-secondary institutions, involving course work, group-based immersion, and self-directed learning, our findings indicate that a multi-pronged approach is a must. According to our research participants, Indigenous language learning would ideally involve curricular and extracurricular opportunities, including safe spaces for Indigenous pedagogies and land-based learning. We are hoping that all post-secondary institutions will eventually offer prospective language students a meaningful learning continuum with an abundance of access points to Indigenous languages and that our research may advance this work.

This study was approved by the University of Guelph Research Ethics Board. Research for this study was supported by the Social Sciences and Humanities Research Council (SSHRC). 


\section{About the Authors}

Dr. Aleksandra Bergier is a Polish settler researcher with an academic background in sociology and cultural studies. She has collaborated with Indigenous communities on research exploring revitalization strategies for Indigenous languages and cultures that place the process of language shift reversal and cultural recovery within a healing continuum of resilient reintegration and address the impacts of intergenerational trauma induced by colonization processes.

Dr. Kim Anderson is a Métis scholar with a PhD in history from the University of Guelph. She holds a Canada Research Chair in Indigenous Relationships and is an Associate Professor in the Department of Family Relations and Applied Nutrition at the University of Guelph. Dr. Anderson has published seven books, the latest being a co-produced memoir with Anishinaabe artist Rene Meshake, entitled Injichaag, My Soul in Story: Anishinaabe Poetics in Art and Words (University of Manitoba Press, 2019), winner of the 2020 Indigenous Voices Award for works published in an Indigenous language. 


\section{References}

Aguiar, W., \& Halseth, R. (2015). Addressing the healing of Aboriginal adults and families within a community-owned college model. National Collaborating Centre for Aboriginal Health. University of Northern British Columbia.

Albury, N. J. (2015). Objectives at the crossroads: Critical theory and self-determination in Indigenous language revitalization. Critical Inquiry in Language Studies, 12(4), 256282. https://doi.org/10.1080/15427587.2015.1096732

Anderson, K. (2011). Life stages and Native women: Memory, teachings, and story medicine. University of Manitoba Press.

Association of Canadian Deans of Education. (2011). Accord for Indigenous education: Progress report 2011. https://www.twu.ca/sites/default/files/accord-forindigenous-education-progress-report.pdf

Battiste, M. (2013). Decolonizing education: Nourishing the learning spirit. UBC Press, Purich Publishing Ltd.

Bergier, A. (2015). Gidizhigiizhwewinaanan: Our languages. Language transfer practices in urban Indigenous communities. Ontario Federation of Indigenous Friendship Centres.

Bliss, H., \& Breaker, N. (2018). Language revitalization in Treaty 7 Territory: The school of languages, linguistics, literatures, and cultures' responsibility to the Siksika, Stoney Nakoda, and Tsuut'ina communities. Report prepared for the Faculty of Arts, University of Calgary.

Bombay, A., Matheson, K., \& Anisman, H. (2009). Intergenerational trauma: Convergence of multiple processes among First Nations peoples in Canada. Journal of Aboriginal Health, 5(3), 6-47.

Bombay, A., Matheson, K., \& Anisman, H. (2013). The intergenerational effects of Indian residential schools: Implications for the concept of historical trauma. Transcultural Psychiatry, 51(3), 320-338. https://doi.org/10.1177/1363461513503380

Borrows, John. (2010). Drawing out law: A spirit's guide. University of Toronto Press.

Brant Castellano, M. (2014). Indigenizing education. Education Canada, 54(3), 10.

Braun, V., \& Clarke, V. (2013). Successful qualitative research: A practical guide for beginners. Sage Publications.

Brittain, J. (2002, April). The heartbeat is strong: Aboriginal language maintenance and revitalization in Newfoundland and Labrador. Unpublished paper presented at Memorial University of Newfoundland. 
Campbell, L., \& Belew, A. (Eds.). (2018). Cataloguing the world's endangered languages. Routledge.

Carli, V. (2012). The city as a "space of opportunity": Urban Indigenous experiences and community safety partnerships. In D. Newhouse, K. FitzMaurice, T. McGuire-Adams, \& D. Jette, (Eds.) Well-being in the urban Aboriginal community. Fostering Biimaadizwin, a national research conference on urban Aboriginal peoples. (pp.1-21). Thompson Educational Publishing, Inc.

Carrière, J., \& Richardson, C. (2017). Calling our families home: Métis peoples' experiences with child welfare. John Charlton Publishing.

Corbiere, M.A. (2019, Spring). Protecting Indigenous language rights: Much more than campus signage needed. Academic Matters. OCUFA's Journal of Higher Education, 1620. https://academicmatters.ca/assets/AcademicMatters_Spring2019.pdf

Council of Ontario Universities. (2017). Deepening our relationship: Partnering with Aboriginal communities to strengthen Ontario campuses. Council of Ontario Universities. https://ontariosuniversities.ca/wpcontent/uploads/2017/08/Deepening-Our-Relationship-Report.pdf

Cull, I., Hancock, R., McKeown, S., Pidgeon, M., \& Vedan, A. (2018). Pulling together: A guide for front-line staff, student services, and advisors. https://opentextbc.ca/indigenizationfrontlineworkers/

Czaykowska-Higgins, E., Burton, S., Marinakis, A., \& McIvor, O. (2017). Supporting Indigenous language revitalization through collaborative post-secondary proficiency-building curriculum. Language Documentation and Description, 14, 136159. https://dspace.library.uvic.ca//handle/1828/9372

De Jong, N., Groenhout, R., Schoonen, R., \& Hulstijn, J. (2015). Second language fluency: Speaking style or proficiency? Correcting measures of second language fluency for first language behavior. Applied Psycholinguistics, 36(2), 223-243. https://doi.org/10.1017/S0142716413000210

Dion, S. D., \& Salamanca, A. (2014). inVISIBILITY: Indigenous in the city - Indigenous artists, Indigenous youth and the project of survivance. Decolonization: Indigeneity, Education \& Society, 3(1), 159-188. https://jps.library.utoronto.ca/index.php/des/issue/view/1541

Drawson, A., Toombs, E., \& Mushquash, C. (2017). Indigenous research methods: A systematic review. International Indigenous Policy Journal, 8(2). https://doi.org/10.18584/iipj.2017.8.2.5

Dunlop, B., Gessner, S., Herbert, T., \& Parker, A. (2018). First Peoples' cultural council report on the status of B.C. First Nations languages. First People's Cultural Council. 
https://fpcc.ca/resource/fpcc-report-of-the-status-of-b-c-first-nations-languages2018/

Environics Institute. (2010). Urban Aboriginal peoples study. Environics Institute.

Farrell-Racette, S. (2017, February). Kitchen logic. Paper presented at the Sakewawak Storytellers Festival, Regina.

First Nations Centre. (2005). First Nations regional longitudinal health survey (RHS) 2002/03: Results for adults, youth, and children living in First Nations communities. First Nations Centre.

Gaudry, A., \& Lorenz, D. (2018). Indigenization as inclusion, reconciliation, and decolonization: Navigating the different visions for Indigenizing the Canadian academy. AlterNative: An International Journal of Indigenous Peoples, 14(3), 218-227. https://doi.org/10.1177/1177180118785382

Gaywish, R., \& Mordoch, E. (2018). Situating intergenerational trauma in the educational journey. In Education, 24(2), 3-23.

https://ineducation.ca/ineducation/article/view/386/964

Green, J. (2017). Pathways to creating Onkwehonwehnéha speakers at Six Nations of The Grand River Territory. Six Nations of the Grand River Territory: Six Nations Polytechnic.

https://www.snpolytechnic.com/sites/default/files/docs/research/pathways_to_cr eating_speakers_of_onkwehonwehneha_at_six_nations.pdf

Grenoble, L. A., \& Whaley, L. J. (2006). Saving languages: An introduction to language revitalization. Cambridge University Press.

Harrison, B., \& Papa, R. (2005). The development of an Indigenous knowledge program in a New Zealand Maori-language immersion school. Anthropology \& Education Quarterly, 36(1), 57-72. https://hdl.handle.net/10289/1359

Hermes, M. (2007). Moving toward the language: Reflections on teaching in an Indigenousimmersion school. Journal of American Indian Education, 46(3), 54-71. http://www.jstor.org/stable/24398543

Hinton, L. (2003). How to teach when the teacher isn't fluent. In J. Reyhner, O. Trujillo, R. Carrasco, \& L. Lockard (Eds.), Nurturing Native languages (pp. 79-92). Northern Arizona University Press.

Indspire. (2018). Post-secondary experience of Indigenous students following the Truth and Reconciliation Commission. Indspire. https://indspire.ca/wpcontent/uploads/2019/10/PSE-Experience-Indigenous-Students-Survey-SummarySept2018.pdf 
Kahakalau, K. (2017). Developing an Indigenous proficiency scale. Cogent Education, 4(1). https://doi.org/10.1080/2331186X.2017.1377508

Kovach, M. (2010). Indigenous methodologies: Characteristics, conversations, and contexts. University of Toronto Press.

Kuokkanen, R. (2011). Reshaping the university: Responsibility, Indigenous epistemes, and the logic of the gift. UBC Press.

Liddicoat, A. J. (2018). Language planning in universities: Teaching, research and administration. Routledge.

Lindstrom, G. E. (2018). Trauma and resilience in Aboriginal adult learners' post-secondary experience [Unpublished doctoral thesis]. University of Calgary.

https://prism.ucalgary.ca/bitstream/handle/1880/106563/ucalgary_2018_lindstro m_gabrielle.pdf?sequence $=3$

McCarty, T. L. (2003). Revitalising Indigenous languages in homogenising times. Comparative Education, 39(2), 147-163. https://doi.org/10.1080/03050060302556

McCue, D. (2016, January 14). Skwomesh language activist to launch 'trailblazing' immersion course at B.C. university. https://www.cbc.ca/news/indigenous/skwomeshlanguage-activist-b-c-university-launch-immersion-course-1.3404541

McIvor, O. (2005). The contribution of Indigenous heritage language immersion programs to healthy early childhood development. Research Connections Canada: Supporting Children and Families, 12, 5-20. https://epub.sub.unihamburg.de//epub/volltexte/2009/3179/pdf/rc_eng12.pdf

McIvor, O. (2015). Adult Indigenous language learning in western Canada: What is holding us back? In K. Michel, P. Walton, E. Bourassa, \& J. Miller (Eds.), Our living languages: Papers from the $19^{\text {th }}$ stabilizing Indigenous languages symposium, (pp. 37-49). Linus Learning.

McIvor, O., \& Anisman, A. (2018). Keeping our languages alive: Strategies for Indigenous language revitalization. In Y. Watanabe (Ed.), Handbook of cultural security (pp. 90109). Edward Elgar Publishing

McIvor, O., Napoleon, A., \& Dickie, K. M. (2009). Language and culture as protective factors for at-risk communities. Journal of Indigenous Health, 5(1), 6-25. https://doi.org/10.18357/ijih51200912327 
McIvor, O., Rosborough, T., McGregor, C., \& Markinakis, A. (2018). Lighting a fire: Community-based Indigenous language teacher education. In P. Whitinui, C. Rodriguez, \& O. McIvor, (Eds.). Promising practices in Indigenous teacher education, (pp. 189-204). Springer.

Meissner, S. (2018). The moral fabric of linguicide: Un-weaving trauma narratives and dependency relationships in Indigenous language reclamation. Journal of Global Ethics, 14(2), 266-276. https://doi.org/10.1080/17449626.2018.1516691

Meshake, R. \& Anderson, K. (2019). Injichaag: My soul in story. University of Manitoba Press.

Mitchell, T., Thomas, D., \& Smith, J. (2018). Unsettling the settlers: Principles of a decolonial approach to creating safe(r) spaces in post-secondary education. American Journal of Community Psychology, 62(3-4), 350-363. https://doi.org/10.1002/ajcp.12287

Mordoch, E., \& Gaywish, R. (2011). Is there a need for healing in the classroom? Exploring trauma-informed education for Aboriginal mature students. In Education, 17(3), 96106. https://ineducation.ca/ineducation/article/view/75

Ontario Federation of Indigenous Friendship Centres (2016). "Ask me about trauma and I will show you how we are trauma-informed": A study on the shift toward traumainformed practices in schools. https://ofifc.org/wpcontent/uploads/2020/03/Trauma-Informed-Schools-Report-2016.pdf

Profitt, N. J. (2000). Women survivors, psychological trauma, and the politics of resistance. The Haworth Press.

Reder, D. (2007). Âcimisowin as theoretical practice: Autobiography as Indigenous intellectual tradition [Doctoral dissertation. University of British Columbia].

Robbins, J., Linds, W., Ironstand, B., \& Goodpipe, E. (2017). Generating and sustaining positive spaces: Reflections on an indigenous youth urban arts program. AlterNative : an International Journal of Indigenous Peoples, 13(3), 161-169. https://doi.org/10.1177/1177180117714406

Shaw, P. (2001). Negotiating against loss: Responsibility, reciprocity, and respect in endangered language research. In F. Endo (Ed.), Proceedings of the 2nd international conference on the endangered languages of the Pacific Rim (ELPR) (pp. 1-13). ELPR.

Skrodzka, M., Hansen, K., Olko, J., \& Bilewicz, M. (2020). The twofold role of a minority language in historical trauma: The case of Lemko minority in Poland. Journal of Language and Social Psychology, 39(4), 551-566.

https://doi.org/10.1177/0261927X20932629

Smith, L. (2012). Decolonizing methodologies: Research and Indigenous peoples (2nd ed.). Zed Books. 
Statistics Canada. (2017). Census in brief: the Aboriginal languages of First Nations people, Métis and Inuit. https://www12.statcan.gc.ca/census-recensement/2016/as-sa/98200-x/2016022/98-200-x2016022-eng.cfm

Sterzuk, A., \& Fayant, R. (2016). Towards reconciliation through language planning for Indigenous languages in Canadian universities. Current Issues in Language Planning, 17(3-4), 332-350. https://doi.org/10.1080/14664208.2016.1201239

Truth and Reconciliation Commission of Canada. (2015). Honouring the truth, reconciling for the future: Summary of the final report of the Truth and Reconciliation Commission of Canada.

http://www.trc.ca/assets/pdf/Honouring_the_Truth_Reconciling_for_the_Future_Jul y_23_2015.pdf

Tuck, E. (2009). Suspending damage: A letter to communities. Harvard Educational Review, 79(3), 409-428. https://doi.org/10.17763/haer.79.3.n0016675661t3n15

UNESCO. (2020). Los Pinos Declaration [Chapoltepek] - Making a Decade of Action for Indigenous Languages. https://en.unesco.org/sites/default/files/los_pinos_declaration_170720_en.pdf

Universities Canada. (2017). Facts and stats. https://www.univcan.ca/facts-andstats/stats/30-indigenous-languages-taught-canadian-universities/

University of Guelph, Mohawk College, Six Nations Polytechnic (n.d.). Journeying towards holistic wellness: A resource for First Nations, Métis and Inuit students. https://www.uoguelph.ca/studentexperience/system/files/JourneyTowardsHolistic Wellness.pdf

Whalen, D., Moss, M., \& Baldwin, D. (2016). Healing through language: Positive physical health effects of indigenous language use. F1000Research, 5, 852. https://doi.org/10.12688/f1000research.8656.1

Whitbeck, L., Adams, G., Hoyt, D., \& Chen, X. (2004). Conceptualizing and measuring historical trauma among American Indian people. American Journal of Community Psychology, 33(3-4), 119-130. https://doi.org/10.1023/B:AJCP.0000027000.77357.31

Wilson, S. (2008). Research is ceremony: Indigenous research methods. Fernwood Publishing.

Wyman, L.T. (2012). Youth culture, language endangerment and linguistic survivance. Multilingual Matters.

Young, M.I., Joe, L., Lamoureux, J., Marshall, L., Moore, D., Orr, J.L., Parisian, B. M., Paul, K., Paynter, F., \& Huber, J. (Eds.). (2012). Warrior women: Remaking postsecondary places through relational narrative inquiry. Emerald Group Publishing Limited. 